\title{
Understanding Chinese Kāi and Guān When Reminding People to Switch Mobile Mode
}

\author{
Chunying Wang \\ Lunghwa University of Science and Technology, Taoyuan, Taiwan \\ cwang@gm.lhu.edu.tw
}

DOI : http://doi.org/10.36892/ijlls.v2i3.288

\begin{tabular}{|c|c|}
\hline $\begin{array}{l}\text { Received: } \\
\text { 25/04/2020 }\end{array}$ & $\begin{array}{l}\text { Abstract } \\
\text { This study investigates why Taiwanese identically understands both Mandarin }\end{array}$ \\
\hline $\begin{array}{l}\text { Accepted: } \\
\text { 27/08/2020 }\end{array}$ & $\begin{array}{l}\text { expressions 請將手機開震動/qìng jiāng shǒu jī kāi zhèn dòng and 請將手機 } \\
\text { 關震動/q̌ing jiāng shǒu jī guān zhèn dòng, which both mean please set your }\end{array}$ \\
\hline $\begin{array}{l}\text { Keywords: } \\
\text { relevance theory; } \\
\text { embodiment; figure } \\
\text { and ground; mobile } \\
\text { phone; Chinese }\end{array}$ & $\begin{array}{l}\text { phone to vibrate. Four perspectives can be employed to explain. Firstly, the } \\
\text { embodiments or imageries of 開/kāi/open and 關/guān/close function in the } \\
\text { expressions. However, only examining both expressions via imageries is } \\
\text { insufficient to explain all the aspects. Relevance theory and the figure and } \\
\text { ground relationship influence people's selection of the expressions because } \\
\text { the focus is different. Finally, people may directly connect the two actions kāi } \\
\text { and guān to a single action, 按/àn/press, because of the development of } \\
\text { touchscreen technology. Therefore, kāi and guän become similar under the } \\
\text { context of reminding people to change their mobile into silent or vibration } \\
\text { mode because no matter which expression is heard, the only action people } \\
\text { have to do is to press or touch a specific icon on their smartphones. The } \\
\text { improvement of technology affects people's experiences of the world, which } \\
\text { may further influence people's cognition. }\end{array}$ \\
\hline
\end{tabular}

\section{RESEARCH RATIONALE}

Smartphones not only change people's lives, but they also change the meaning of some words in Mandarin Chinese. Smartphones generally have different modes, such as silent, vibration, and sound. People can switch their phones to different settings as and when required. However, two words, kāi and guān (Chen, 2017) are mainly used to remind people to 'turn on' or 'turn off' their phones into vibration or silent modes. The following example is a sentence in Mandarin requesting people to set their phones to vibrate. The examples presented in this study are spoken in everyday life in Taiwan. The Mandarin expression is illustrated in the first section, the Pinyin of each character with its tone marker is demonstrated in the second section, and the translation of the Mandarin sentence is provided in the final section.

\section{1.請將手機開震動。 \\ qǔng jiāng shǒu jī kāi zhèn dòng \\ Please set your phone to vibrate.}

However, example 2 contains an alternation, which has an identical meaning and function as example 1 .

\author{
2.請將手機關震動。 \\ qǔng jiāng shǒu jī guān zhèn dòng
}


Please set your phone to vibrate.

When comparing examples 1 and 2, the components of each sentence are almost the same, but the verbs are varied. The same condition can be found when people are required to switch their phone to silent mode. For instance,

\section{3.請將手機開靜音。 \\ qǔng jiāng shǒu jī kāi jìng yīn}

Please turn your phone on silent.

\section{4.請將手機關靜音。 \\ qǐng jiāng shǒu jī guān jìng yīn \\ Please turn your phone on silent.}

When examining the meanings of both words, the verb in examples 1 and 3 is kāi, which means 'open', while the verb guān in examples 2 and 4 refers to 'close' (Ministry of Education ROC, 2015). Taken literally, they should be a pair of antonyms in Chinese (Jones, 2002), but each pair of examples, e.g. $1 \& 2$ and $3 \& 4$, have identical meanings. The former pair requires people to set their smartphone to vibrate and the latter, to silent mode. Nevertheless, when guān is followed by the default mode to ask people to change their phone mode, e.g. 關鈴聲/guān líng shēng, it means to turn off the sound mode. In other words, 關鈴 聲/guān líng shēng does not have the meaning of “turning on the sound mode" but only 開鈴 聲/kāi líng shēng does. Why do Taiwanese people identically understand Mandarin kāi and guān when they are reminded to turn on the silent and vibrate modes but kāi and guān retain their original meanings when the following noun is the sound mode? Therefore, the aim of this study is to understand why kāi and guān express an undistinguishable meaning in everyday conversation in Mandarin Chinese, when the context is asking people in Taiwan to change the mode of their smartphones to silent or vibrate model.

Accordingly, the purpose of the paper is to investigate both of the words, kāi and guān, in order to understand why the opposite words have an identical function in the context of a smartphone. In order to discuss their usage, the meaning and function of each word are reviewed first, and it is assumed that there is a cognitive process in operation in people's minds when they process the opposite words in the context of being asked to change their phone into another mode.

\section{LITERATURE REVIEW}

\section{Meaning of kāi and guān}

According to the dictionary produced by the Ministry of Education ROC (2015), both kāi and guān are verbs and they are obviously opposites. Kāi means 'to open' or ‘to turn on'. For example, 開門/kāi mén refers to 'open the door' and 開燈/kāi dēng means 'to turn on the light'. Conversely, guān means 'to close' or 'to turn off', e.g. 關門/guan mén means 'to close the door' and 關燈/guān dēng means 'to turn off the light'.

However, these two verbs can form a compound noun when one is syntactically merged with the other, e.g. 開關/kāi guan, which refers to 'a switch' (Ministry of Education ROC, 2015; Zhang, 2007). According to Zuoyan and Likun (2013, p. 7), this pattern of verb-verb 
combination indicates the purpose or function of the compound noun. As a result, 開關/kāi guan points to 'a tool' used to open (turn on) and close (turn off) something.

Moreover, because kāi and guān have opposite meanings, they are a pair of antonyms (Clark, 1970; Jones, 2002, p. 1; Lyons, 1977). The concept of an antonym is vital because the association between antonyms expresses ideas that influence people's understanding. For example, it is necessary to comprehend the concept of 'high' in order to understand the concept of 'low'. Although high and low are contradictory concepts, they are related to each other. Brugman and Lakoff (1988) argue that concepts can be connected with each other. They use the example of an arc and a circle to explain this idea because it is only possible to comprehend the concept of an arc based on an understanding of a circle. The concept of a circle functions as the basis (secondary focus) of the profile (primary focus) (Croft, 1993; Langacker, 2008), which, in this case, is 'arc'. In terms of kāi and guān, the meaning of each word depends on the meaning of the other. The notion of 'open' can only be understood by simultaneously learning the concept of 'close'.

Nevertheless, when both kāi and guān are modified and followed by the adverb —半 /yībàn, which means 'partly' or 'half', it seems to weaken the opposite meanings embedded in kāi and guān, as illustrated in Examples 5 and 6.

5.門開一半
mén kāi yī bàn
The door is partly opened.

\section{6.門關一半 \\ mén guān yī bàn \\ The door is partly closed.}

$\mathrm{Li}$ and Thompson (1989, p. 283) remind us that the phrase underlined in Examples 5 and 6 is called a 'quantitative adverb phrase', which, for them, is the structure of a number, a classifier, and a noun, which functions to present the duration or degree of an action. Notably, the classifier can be converted if necessary. In other words, the classifier is not employed if the phrase-final noun is essentially a measure word. Hence, the quantitative adverb phrase, 半/yībàn, shows the degree of kāi and guān as presented in Examples 5 and 6. Both sentences describe the same condition of 'a not fully opened and not fully closed door'. Although the verbs in Examples 5 and 6 are altered, the situation portrayed by both sentences is almost identical.

Nevertheless, the kāi and guān in Examples 5 and 6 do not really become synonyms because individuals are inclined to select a different focus and standpoint to form their linguistic expressions. Examples 5 and 6 show different descriptions of a particular context. Dirven and Verspoor (2004) and Langacker (2008, pp. 55-89) call this 'construal', which denotes an alternative process of experiencing and describing identical content. Construal can be caused by many factors, including specificity, focus, prominence, and perspective. The degree of specificity is increased when elaborating the details of something. For instance, there is a greater degree of specificity in 'a red luxury Burberry scarf' than 'a scarf'.

In addition to specificity, individuals tend to choose different aspects of a concept in their speech (Ungerer \& Schmid, 2013). For instance, they can say both 'a half empty glass of water' and 'a half full glass of water' to describe the identical context of a glass partially occupied by water. Furthermore, individuals' vantage point influences their use of construal (Langacker, 2008, p. 73). For instance, reverting to Examples 5 and 6, people may want to emphasise different aspects of the same context and select either kāi or guān to describe it. 
However, 開震動/kāi zhèn dòng and 關震動/guān zhèn dòng syntactically show a verbobject compound pattern, which means the second phrase presents the object which has undergone the actions kāi and guān. Therefore, whether it is 開震動/kāi zhèn dòng or 關震動 /guān zhèn dòng, the underlined part, the vibration mode, is the object of the 'turn on' or 'turn off' of the appointed function. Like in 開門/kāi mén and 關門/guān mén, kāi and guān should have different meanings. Thus, what causes 開震動/kāi zhèn dòng and 關震動/guān zhèn dòng to have a similar meaning is still unknown.

\section{Embodiments of kāi and guān vs. turn on and turn off}

In light with Lakoff and Johnson (1980), people's conceptual system is grounded via their bodily interaction with the world. For instance, people's spatial concepts about up and down are structured from their body movement, which is governed by a motor programme. Furthermore, Gibbs and Colston (2006) argue people's perception and comprehension are deeply influenced by image schemas, which is defined as 'schematised patterns of activity abstracted from everyday bodily experiences, especially pertaining to vision, space, motion, and force' (Langacker, 2008, p. 32). People's bodily experience forms their image schema which evokes people's mental representation.

The actions kāi and guān play important roles in people's everyday life because people frequently kāi and guān something, e.g. open/close a door and turn on/off the light. People's embodiments about kāi and guān can be mainly related to the concepts of appearance and disappearance (Lindstromberg, 2010; Nishimura, 2007). When an individual opens a door, things behind the door appear in one's vision. Identically, when someone turns the light on, the brightness emerges. By contrast, when one closes a door or turns off the light, the things behind the door or the light become invisible, which refers to the sense of disappearance.

The image schema of kāi and guān can be clarified by investigating their counterparts in English, which are turn on and turn off. Wang (2014) indicates English and Mandarin Chinese have some similarities on a conceptual level. Kāi and guān the light refers to English turn on the light and turn off the light. The imagery of the two particles on and off should also be considered in the investigation. Imagery is defined as 'a process (not a structure) by which sensory information is represented in the working memory' (MacInnis \& Price, 1987, p. 437). Mental imagery functions to support people's thinking processes, such as spatial reasoning, problem solving, and mental discovery (Cornoldi, De Beni, \& Pearson, 2016, p. 1). In addition, Fodor (1981) defines imagery, which is functionally similar to 'image', as the way individuals cognitively distinguish representation. However, imagery not only has an intimate relationship with memory, also known as a storage process, but also with an active process (Cornoldi et al., 2016, p. 5). The concept of an active process is like Langacker's (2002, 2008) 'active zones', which denote that a concept, as well as a mental representation, can be organised into a figure and a ground. The figure is the more active part, while the ground is a relatively inactive part of the representation (Croft, 1993; Langacker, 2008).

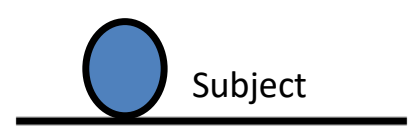

\section{Figure 1. Prototypical meaning of on}

Although on and off do not appear in kāi and guān, like those in turn on and turn off in English, the image schema of appearance and disappearance are deemed to be relevant to kāi 
and guān. Lindstromberg (2010) and Nishimura (2007) provide a very detailed explanation of the imagery of on and off. Lindstromberg (2010, p. 52) considers that the preposition on has two distinctive meanings, one of which is the opposite to the meaning 'off' and the other is the opposite to 'back'. The prototypical meaning of on can be represented by Figure 1, in which the subject is in contact with the line, which is the landmark, thereby supporting the subject. For example, the book is on the table fully describes the prototypical meaning. The book touches the surface of the table, which enables it to withstand gravity. Other than a prototypical meaning, on can also imply the meaning of 'continuity' (Garrod, Ferrier, \& Campbell, 1999; Lindstromberg, 2010, p. 58; Nishimura, 2007, p. 88). Moreover, Nishimura (2007) indicates that on is a kinetic preposition, since it not only presents the static prototypical meaning, but also a variety of movement. For instance, the preposition on in 'walk on and on' extends the duration of walk and makes it a continuous action. Besides, Nishimura (2007) argues that on also contains the imagery of appearance. Nishimura (2007, p. 88) employs the 'sun metaphor' to explain the meaning of on. When the sun rises in the morning, it appears on the opposite side of you and moves continuously without stopping; hence, the conceptual meaning of on is embedded in the imagery of the sun movement metaphor.

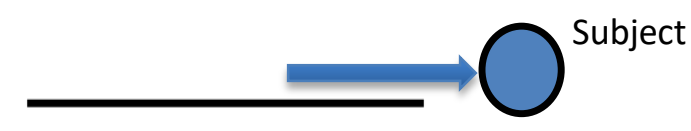

\section{Figure 2. Prototypical meaning of off}

On the contrary, the meaning of 'off' is opposite to 'on' (Lindstromberg, 2010; Nishimura, 2007). Off only has a central meaning, which is "not in contact with" (Lindstromberg, 2010, p. 55), although it is usually extended to mean "leave" (Nishimura, 2007, p. 237). The image of the preposition off is demonstrated in Figure 2. Although the central meaning shows 'not in contact with', it is assumed that there is original contact between the subject and the landmark; therefore, the meaning of 'leave' also implies that there is a starting point of the action. For example, I am off to the office entails a presupposition that I was in the office earlier but I left so I am no longer there. Furthermore, since off is the opposite of on, it also has a sense of 'disappearance' and 'stopping a continuous movement or action' (discontinuity). For example, turn off the light indicates that the light disappears and the original continuing action of lighting stops.

Some grammarians may doubt that the on and off in turn on and turn off are not prepositions because they are 'particles' in the phrasal verbs. A particle is a word with an uninflected grammatical function, but it can also act as a preposition (McArthur, McArthur, \& McArthur, 2005). Lindstromberg (2010) argues that this grammatical question is mainly based on syntax rather than meaning. A phrasal verb is a combination of a verb and a particle and it can be replaced by a single verb, e.g. hand in = submit. Nevertheless, particles definitely provide an additional meaning. For example, the on in turn on implies the meaning of appearance, which cannot be expressed by the single verb 'open'.

Although the present research is focused on kāi and guān in Mandarin Chinese, the imagery or conceptual meaning of kāi and guān, including on and off, is considered to be helpful to the investigation into the reasons why the two opposite words seem to have the same meaning in Example 1 and Example 2. In addition to the meanings of on and off, it is also worth reviewing pragmatics, relevance theory, and the way in which $3 \mathrm{C}$ products influence people's thinking. 
Example 1 and Example 2 should not have the same meaning because kāi and guân have opposite meanings (Ministry of Education ROC, 2015). Taiwanese people identically understand them, under the context of being reminded to change the mode of their mobile phones because of their knowledge of pragmatics, which is the study of how context affects meanings (Yule, 1996). People's utterances do not always express their surface or literal meanings. When the semantic meanings of expressions are failed to be understood, people have to retrieve the meanings by searching information and making inferences. When inferencing, the knowledge of pragmatics and relevance theory function to achieve comprehension because people are inclined to find the most appropriate meaning for nonliteral expressions by searching their mental storage.

Relevance theory (Sperber \& Wilson, 1995, p. 260) functions when people make an inference and it introduces two major principles to explain communication and people's cognitions. First, 'human cognition tends to be geared to the maximisation of relevance' and, second, 'every act of ostensive communication communicates a presumption of its own optimal relevance'. The first principle, also known as a cognitive principle of relevance, denotes every input can evoke cognitive processes and 'cognitive resources tend to be allocated to the processing of the most relevant inputs available' (Sperber \& Wilson, 1995, p. 261). The second principle, which is also called as a communicative principle of relevance, states the ostensive input should be relevant enough to the hearers because they have to believe that doing the searching and making an inference for the input information are worthwhile enough. Additionally, Gibbs and Tendahl (2006) argue people are inclined to search the most relevant information and meanings from their cognition in order to effectively achieve understanding. The searching and inferencing will terminate when the hearers get the meaning. For Tendahl and Gibbs (2008, p. 1831), 'there is a trade-off between cognitive effort and cognitive effects such that listeners will attempt to maximise cognitive effects while minimising cognitive effort'. Thus, when people fail to understand the literal meaning of expressions, they may start to employ the most efficient way to find the most optimal alternative from their cognition. The comprehension will be achieved when they find the most relevant interpretation for an expression under a specific context. Accordingly, it is believed that relevance theory can be brought to examine what causes Taiwanese people identically understand kāi and guān when they are requested to turn off the sound mode on mobiles.

\section{Switch movement on $3 \mathrm{C}$ products}

Because the functions of $3 \mathrm{C}$ products are evolving and the designs may change as time passes, the gadgets affiliated to a $3 \mathrm{C}$ product may be different from the original ones. Chu and Lee (2006, p. 212) research the switch movement on 3C products and find that it can be done through similes, metonyms, and metaphors. The concept of movement when manipulating a 3C product gradually differs as the design of the product becomes more advanced. For example, people may not really 'turn' a switch to activate or deactivate a machine. Different movements can achieve the same goals of 'switching on' and 'switching off' something on a 3C product. For instance, when opening up a foldable mobile phone, this movement can refer to 'answering a phone call'. On the other hand, folding the mobile phone can stop the call function. In this case, the functions of kāi and guān are activated by different movements other than 'turning on' and 'turning off' a power switch.

Chu and Lee (2006) remind us that a designer may transfer the shape of a 3C product to present the formation of this specific item. Each created item has its own signifier and signified meaning. People may acquire the meaning or function of the gadget based on its design and their original experience. For example, if a switch is designed as a button, they 
may directly understand that they can press this button based on their previous experience. Furthermore, the functions of $3 \mathrm{C}$ products can also be deduced from a combination of the forms, but since the design of these products is becoming ever more complex, people may be confused when they fail to understand the meaning by examining their forms.

Based on interviewing 7 males and 5 females, Chu and Lee (2006, p. 215) find that, with the improvement of touch panel technology, the most frequently mentioned switch movements are 按/àn/press, 點/diăn/touch, and 壓/yā/press. In addition to these, some creative terms are also introduced, e.g. 甩/shuăi/swing, 搖/yáo/swing, 滾/gǔn/roll, 切/qiē/cut, and 扯/chě/tear, all of which can refer to the movements of 'turn on' and 'turn off' to some extent. The movement differs because of the shape and manipulation of the $3 \mathrm{C}$ products.

\section{METHODOLOGY}

Since a cognitive process is assumed to be operating in people's minds, which leads them to turn off the sound on their smartphones, a conceptual analysis was used in the present study to investigate the relationship between kāi and guān and the action of setting the phone to vibrate. The main aim of using a conceptual analysis (CA) (Chalmers \& Jackson, 2001; Furner, 2004; Kosterec, 2016, p. 221; Machado \& Silva, 2007), which is also known as a theoretical analysis, is to identify conceptual problems and provide better linguistic knowledge. For Furner (2004, pp. 233-234), "the goal of using a conceptual analysis as a method of inquiry into a given field of interest is to improve our understanding of the way in which particular concepts are (or could be) used for communicating ideas about that field." The results of a CA may be presented as definitions or the relevance between X and Y (Horvath, 2018). More specifically, Kosterec (2016, pp. 221-227) explains that there are three kinds of CAs, a constructive analysis, a detection analysis, and a reductive analysis. A constructive analysis can be motivated by the absence of a clear relationship among the concepts or terms of a language, while a detection analysis can be utilised to answer questions about a certain relationship among concepts. The motivation for a reductive analysis can be when some theories or languages can be applied to infer another theory or language.

Based on Kosterec's (2016) explanation, the CA employed in this paper should be a constructive CA because the relationship between kāi and guān and people's subsequent action is vague. Hence, this research procedure follows Kosterec's (2016, p. 223) model of a constructive CA, which involves firstly describing the background of the initial concept before highlighting the conceptual problem in order to formulate a new conceptual relationship. After investigating the conceptual relationship within a clarified conceptual background, the new relationship should be further elaborated. Finally, when the relationship has been successfully defined, it should be announced as part of the conceptual background.

Accordingly, the research step of the present study includes (1) describing the meaning of kāi and guān and their major usages in Mandarin Chinese, which has been reviewed in Section 1 and Section 2.1; (2) highlighting the research phenomenon, which is that kāi and guān become similar when the context is reminding people to change their mobile mode to vibration or silent mode but not sound mode; (3) investigating varied theories and research to address the indicated conceptual problem; and (4) employing varied possible theories to explain why kāi and guān seem to have the same meaning when the context is asking people to turn off the sound mode, while kāi and guān maintain their original meanings when the following mode is the sound mode, e.g. 關鈴聲/guān líng sheng versus 開鈴聲/kāi líng sheng. With the research procedures, the conceptual relationship 
between kāi and guān and the context of using mobiles is mainly investigated and discussed based on the literature. After elaborating on the relationship, the results can be drawn.

\section{FINDINGS AND DISCUSSION}

As indicated, kāi and guān have opposite meanings in Mandarin Chinese (Ministry of Education ROC, 2015), but they appear to have an identical function when they are employed to ask people to switch their mobiles to a different mode. So, what is the conceptual relationship that gives kāi and guān the same meaning when people are requested to turn off the sound mode on their mobile phones? After reviewing the literature, the relationship can be drawn from four perspectives. Firstly, people's embodiments about kāi and guān as well as the imageries of on and off (Jeannerod, 1994; Lindstromberg, 2010; MacInnis \& Price, 1987; Nishimura, 2007) could explain the meanings between kāi and guān to some extent, although they are both Mandarin characters. However, these imageries need to be discussed with figures and grounds (Brugman \& Lakoff, 1988; Croft, 1993; Langacker, 2008) because the focus differs when kāi and guān are employed in examples 1 or 2 . In addition to figures and grounds relationship, relevance theory (Sperber \& Wilson, 1995) functions to help people make inference and retrieve meanings. Finally, the design and switch movement of a $3 \mathrm{C}$ appliance may also influence people's understanding of the expressions shown by examples 1 to 4 .

\section{Embodiments of kāi and guān}

The Chinese characters kāi and guān are verbs and they mean 'open' and 'close' respectively (Ministry of Education ROC, 2015). In addition, kāi also refers to 'turn on' and guān means 'turn off'. The embodiment of kāi reveals that an original closed entity becomes open. For example, 開門/kāi mén indicates 'to open a closed door'; therefore, the status of the door changes after the action kāi. On the other hand, the imagery of guān indicates the contrary so that an open entity is transformed into a closed one. Nevertheless, the embodiments of kāi and guān are insufficient to fit the images expressed by 請將手機開震動 /qǔng jiāng shǒu jī kāi zhèn dòng, and 請將手機關震動/qǐng jiāng shǒu jī guān zhèn dòng. The changed statuses are not visible and, furthermore, it is not obvious that the object has undergone the actions 'open' and 'close'.

Since Wang (2014) proposes that English and Mandarin Chinese have conceptual differences as well as similarities, the imageries embedded in the English concept of on and off should be considered when investigating the conceptual relationship between kāi and guān and the use of smartphones. When using a smart phone, the counterpart meanings of kāi and guān should be 'turn on' and 'turn off' in English. Obviously, the prepositions on and off do not appear in the Chinese characters, but it is suggested that the imageries of on and off can still be accessed. According to Lindstromberg (2010) and Nishimura (2007), the preposition on not only expresses its prototypical meaning, which is shown in Figure 1, but also the sense of continuity and appearance; on the contrary, off shows the opposite meaning to on. In other words, other than its prototypical meaning, off reveals the sense of 'disappearance' and 'stopping a continuous movement'. Therefore, the expression 'turn on the light' not only means that the status of the light changes from dark to bright, but also implies the emergence of the light, which is the sense of appearance. The sense of continuity is also inclusive because the light continues to work after the switch is turned on. In contrast, 'turn off the light' reveals the imagery of off. Since off presents the inverted meaning of on, the sense of disappearance and discontinuity is definitely expressed in 'turn off the light'. The light disappears and the continuous brightness is stopped because the switch has been turned off (Lindstromberg, 2010; Nishimura, 2007). 
As a result, the conceptual meanings of on and off are suggested to be brought to the study of kāi and guān in the context of switching mobile settings. The senses of continuity and appearance can be expressed by 請將手機開震動/qǐng jiāng shǒu jī kāi zhèn dòng and the conceptual meanings of discontinuity and disappearance can be accessed from 請將手機 關震動/quing jiāng shǒu jī guān zhèn dòng. It is reasonable that a person 'turns on' his smartphone to the vibration mode after he does 開震動/kāi zhèn dòng on it. The vibration mode remains active after the 'turn on' is done. The mode appears and continues to function until it is changed again. However, why is the status of a mobile phone still on vibration mode when an individual 'turns off' his phone to vibrate mode? In other words, if 關震動 /guān zhèn dòng represents the conceptual sense of discontinuity and disappearance (Croft, 1993; Langacker, 2008), why is the phone still on vibration mode after a person 'turns the vibration mode off'? Based on the conceptual sense of off, the vibration mode should disappear and no longer continue to function after the mode is switched off. As can be seen, some contradictions to the phrase 關震動/guān zhèn dòng seem to emerge. It is not enough to give an overview of the two expressions, e.g. examples 1 and 2 , by only invoking the conceptual sense of on and off. Therefore, it is also argued in this study that the concepts of 'active zone', e.g. profile and ground, (Croft, 1993; Langacker, 2008) and relevance theory (Sperber \& Wilson, 1995), to some extent, need to be included in the discussion.

\section{Figure-ground relationship and relevance theory}

It has been shown that kāi and guān are opposite words so it is reasonable that 開鈴聲 /kāi líng sheng and 關鈴聲/guān líng sheng have different meanings. Both verb phrases present a verb-object pattern. As in the phrase 開門/kāi mén, the second part is the object undergoing the action kāi so the door becomes openafter doing kāi. Accordingly, 鈴聲/líng sheng, the sound mode, should be the object or status which is 'turned on' or 'turned off' when people utter 開鈴聲/kāi líng sheng and 關鈴聲/guān líng sheng. In these two utterances, both kāi and guān express their original meanings, which are 'turning on' and 'turning off'. The hearers do not experience difficulty in understand them after receiving the requests. Nevertheless, what makes kāi and guān in Examples 1 and 2 identical? Why do kāi and guān retain their meanings when the following is a sound mode but they become similar when kāi and guān are followed by vibration mode or silent mode?

Although this study employs the embodiments of kāi and guān to provide an explanation, the conceptual meanings of kāi and guān are not sufficient to explain why individuals understand the expressions of Examples 1 and 2 as they have the same meaning and function because the same explanation cannot be applied to 開鈴聲/kāi líng sheng and 關 鈴聲/guān líng sheng. When Taiwanese people are asked to turn off the sound on their mobiles, they may hear either Example 1 and 2. However, as long as guān expresses its original meaning, the purpose of switching off mobile sound cannot be achieved. In order to solve this contradiction, it is additionally proposed that people's vantage point influences their figure and ground selection on the usage of kāi and guān and relevance theory assists their interpretation.

According to Ungerer and Schmid (2013), individuals tend to choose different aspects of a concept in their speech so they are inclined to highlight a specific part and form their utterances. In other words, people's uses of the language express their standpoints and show a relationship between figure and ground (Croft, 1993), which is discussed as the 'action zone' 
by Langacker (2008). The figure, also called the profile, is the primary focus of an expression, while the ground is the secondary focus, which functions as the base of the same expression. When examining 請將手機開震動/qǐng jiāng shǒu jī kāi zhèn dòng and 請將手 機關震動/qǔng jiāng shǒu jī guān zhèn dòng, people may have no problem in understanding the former utterance. Nevertheless, the literal meaning of the latter utterance does not make sense. If the vibration mode is turned off, why does the mobile remain on vibration mode? That is to say, if a function is switched off, it implies a status change and the original status should no longer continue.

Obviously, Taiwanese people don't seem to have difficulties in comprehending 請將 手機關震動/qǔng jiāng shǒu jī guān zhèn dòng. It is believed that people's pragmatic knowledge and relevance theory help people interpret it (Gibbs \& Tendahl, 2006; Sperber \& Wilson, 1995; Yule, 1996). When people process the utterance, the literal meaning fails to fit the speaker's expectation because they are requested to switch off the sound on their mobiles. In order to understand 請將手機關震動/qǐng jiāng shǒu jī guān zhèn dòng, people search the most relevant information from their cognition, compare the information with the context, make an inference, and finally get the most optimal interpretation.

Furthermore, in the case of 請將手機開震動/qǔng jiāng shǒu jī kāi zhèn dòng and 請將 手機關震動/qǐng jiāng shǒu jī guān zhèn dòng, the figure and ground relationship is considered to be varied. The speaker's vantage point is what makes the construal (Dirven \& Verspoor, 2004; Ungerer \& Schmid, 2013). It is suggested that, when an individual forms either the sentences in examples 1 or 2 , the presupposition should be that there is a default setting of the mobile phone, which is on the sound mode. Imagine that you have just bought a new phone and the default setting is on the sound mode. Therefore, when reminding people to switch their phones to vibration or silent mode, a person utters the sentence 請將手機開震 動/qǐng jiāng shǒu jī kāi zhèn dòng or 請將手機關震動/qǐng jiāng shǒu jī guān zhèn dòng. People's vantage points influence their choices of figure and ground relationship and decide the expression they wish to use.

In view of the conceptual meaning of kāi and guān, a mode is activated and appears because something is 'turned on' and the function should be deactivated and disappear when something is 'turned off'. In 請將手機開震動/qǔng jiāng shǒu jī guān zhèn dòng, what is 'turned on' is the vibration mode, while it is the sound mode that is 'turned off' but not the vibration mode in 請將手機關震動/qǐng jiāng shǒu jī guān zhèn dòng. Taiwanese people understand 請將手機關震動/qǐng jiāng shǒu jī guān zhèn dòng as it is reminding them to switch their mobile to a vibration mode because the figure and ground relationship is different from 請將手機開震動/qǐng jiāng shǒu jī guān zhèn dòng.
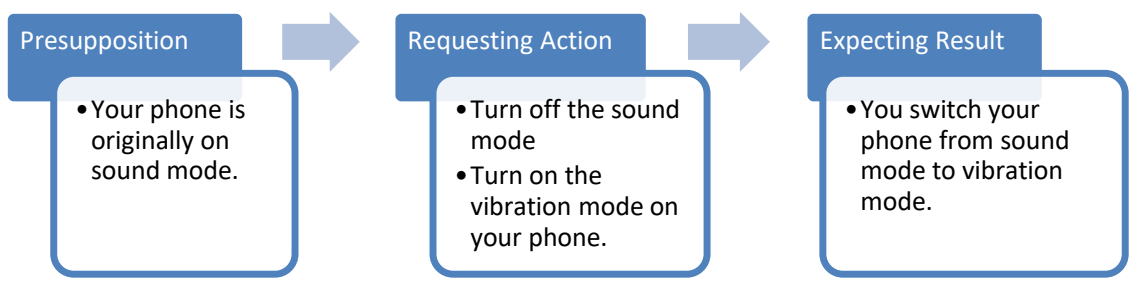

Figure 3. Scenario: 請將手機開震動/qǐng jiāng shǒu jī käi zhèn dòng and 請將手機關震動/qǐng 
When both sentences are said to remind people to turn on the vibration mode on their phone, the vibration mode appears as the result of the action 'turn on' or 'turn off'. This scenario is illustrated in Figure 3. Firstly, it is supposed that the phone is on sound mode, which is the presupposition, and the speaker then wants the phone set to vibrate by emphasising 'please turn on (turn off) your phone to vibration mode'. Finally, the phone is set to vibration mode.

The figure and ground relationship in 請將手機開震動/qǐng jiāng shǒu jī kāi zhèn dòng is illustrated in Figure 4. Because of the verb kāi, its following noun, the vibration mode, should be more salient and this is the figure of this expression. In other words, the presupposition, which is that the phone is originally in sound mode, functions as the ground. Although the presupposed status of the phone is not mentioned, it still exists (Croft, 1993; Langacker, 2008). This statement does not emphasise the original status of the mobile phone by simply reminding the owner to change the status of the phone to vibration mode.

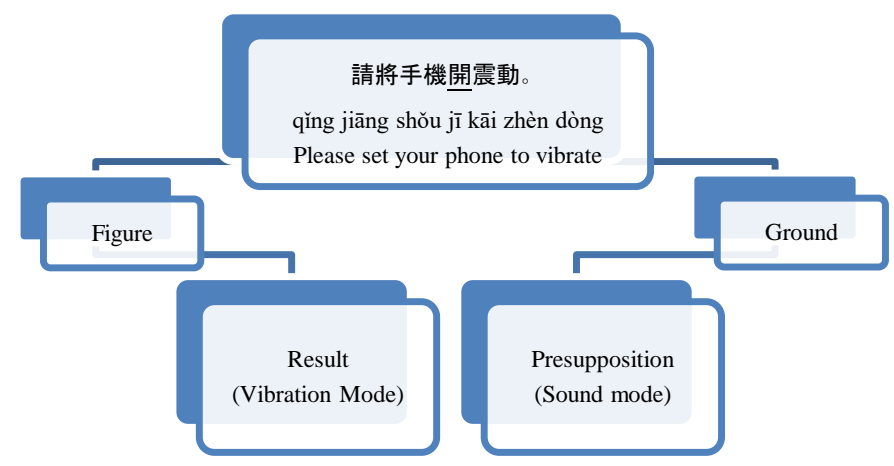

\section{Figure 4. Figure and ground relationship in 請將手機開震動/q̌̌ng jiāng shǒu jī käi zhèn dòng}

On the contrary, an opposite figure and ground relationship to Figure 4 is shown in Figure 5. In terms of the switch movement on a mobile phone, a specific mode is closed by turning on another function. What is salient in 請將手機關震動/qǔng jiāng shǒu jī guān zhèn dòng is 'the mode which is closed'. In other words, the figure is the unmentioned presupposition, which is the original default on the listeners' phone. After performing the action guān, the sound mode is obviously hidden or has disappeared and is replaced by the vibration mode, which is the result of 關震動/guān zhèn dòng, as well as the ground in this expression. The sound mode is simultaneously turned off when the vibration mode is turned on.

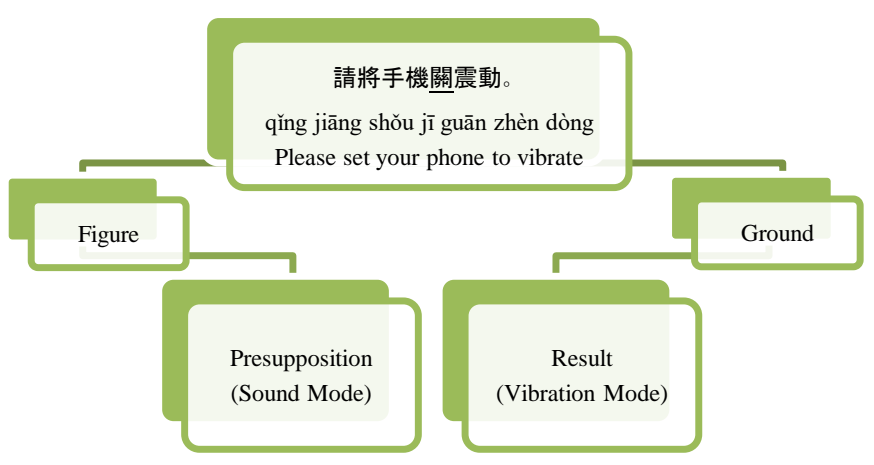




\section{Figure 5. Figure and ground relationship in 請將手機開震動/qǐng jiāng shǒu jī kāi zhèn dòng}

\section{The switch metaphor on smartphones}

Chu and Lee (2006) propose that the cognition of the switch movement can vary based on the user's intention and the development of $3 \mathrm{C}$ products. For mobile phones, the touchscreen technology enables people do almost everything with a touch of their fingers. In addition, Chu and Lee (2006) find that the switch motion that most frequently appears on 3C products is 按/àn, which can refer to 'to press' or 'to touch' in English. This motion can be employed to kāi and guān enormous applications and functions on a smartphone. Therefore, it is possible that, when using a mobile phone, people can easily understand the two motions kāi and guān by means of a single action, 按/àn/press.

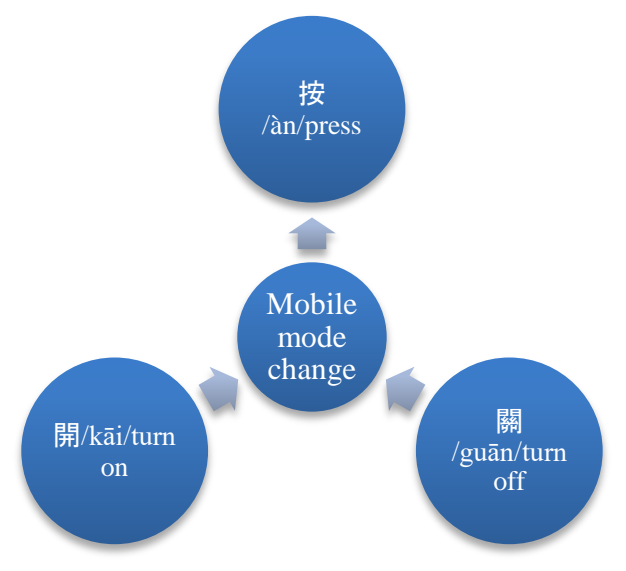

\section{Figure 6. Switch Motions on Mobiles}

The switch motions kāi and guān with a mobile setting are shown in Figure 6 . In the context of using a mobile phone, whether it is 開震動/kāi zhèn dòng or 關震動/guān zhèn dòng, the only action that most people have to take on their smartphones is to 'press' a specific icon to transfer one mode to another; therefore, people's cognition of kāi and guān becomes closer with this action to some extent. They may direct both kāi and guān to the motion 按/àn/press and understand examples 1 and 2 by simply pressing an icon. This could be one of the reasons why the opposite words become similar.

\section{CONCLUSION}

In summary, why the functions and meanings of kāi and guān in examples 1 and 2 appear to be similar can be explained from four perspectives. Firstly, the embodiments and conceptual meanings of kāi and guān need to be considered because something exactly appears or disappears when one of specific actions is performed (Lindstromberg, 2010; Nishimura, 2007). The sense of continuity or discontinuity is also embedded in the two verbs kāi and guān. Nevertheless, employing their conceptual senses is insufficient to explain both expressions. As can be seen, the concept of figure and ground (Croft, 1993; Dirven \& Verspoor, 2004; Langacker, 2008; Ungerer \& Schmid, 2013) plays an important role between 請將手機開震動/qǐng jiāng shǒu jī kāi zhèn dòng and 請將手機關震動/qǐng jiāng shǒu jī guān zhèn dòng. The verb employed in the expression indicates a more emphasised focus. For example, the result of the verb phrase is more active than the ground for 請將手機開震 
動/qǐng jiāng shǒu jī kāi zhèn dòng; in contrast, the previous mode of a phone before switching to vibrate is potentially marked by 請將手機關震動/qǐng jiāng shǒu jī guān zhèn dòng. Although the results of both sentences are the same, the figure and ground relationship are varied. Besides, relevance theory (Sperber \& Wilson, 1995) functions when people process those utterances because they have to deal with how antonyms become similar under the context of using mobiles. Last but not least, the switch motions on 3C products (Chu \& Lee, 2006) may alter people's cognition of kāi and guān. Due to the modern touchscreen technology, people can perform both actions by an individual motion on their phone, which is 按/àn/press. When using a smartphone, people may directly connect the switch movement kāi and guān to 按/àn/press. Therefore, an identical result and understanding can be reached when hearing either 請將手機開震動/qǔng jiāng shǒu jī kāi zhèn dòng or 請將手機關震動 /qǔng jiāng shǒu jī guān zhèn dòng. These explanations can be applied to clarify the two expressions, since they both mean 'please switch your phone to silent mode'.

In conclusion, although people's understanding of the two words kāi and guān in the context of reminding people to switch their mobiles to vibrate or silent mode is similar, the cognitive mechanism in people's minds is definitely different and complex. As can be seen, it is not enough to only bring the embodiments of kāi and guān into the explanation. A more elaborative cognitive process can be deduced and drawn by combining relevance theory and the figure-ground relationship. Furthermore, the improvement of technology also affects people's experience of the world. People's behaviour may change, as well as their usage and understanding of language, accompanied by new technology.

\section{REFERENCES}

Brugman, C., \& Lakoff, G. (1988). Cognitive topology and lexical networks. In Lexical ambiguity resolution (pp. 477-508). Morgan Kaufmann. doi:10.1016/B978-0-08-051013$\underline{2.50022-7}$

Chalmers, D. J., \& Jackson, F. (2001). Conceptual analysis and reductive explanation. The Philosophical Review, 110(3), 315-360.

Chen, J. (2017). When transparency doesn't mean ease: learning the meaning of resultative verb compounds in Mandarin Chinese. Journal of Child Language, 1-24.

Chu, S.-T., \& Lee, C.-F. (2006). A study on the form phrase of switch movement with semantics perspective for 3C products. Journal of Design(6), 210-218.

Clark, H. H. (1970). Word associations and linguistic theory. In J. Lyons (Ed.), New horizons in linguistics. London: Penguin.

Cornoldi, C., De Beni, R., \& Pearson, D. (2016). The generation, maintenance, and transformation of visuo-spatial mental images. In Imagery, Language and Visuo-Spatial Thinking (pp. 1-28). Oxfordshire: Routledge.

Croft, W. (1993). The role of domains in the interpretation of metaphors and metonymies. Cognitive Linguistics, 4(4), 335-370.

Dirven, R., \& Verspoor, M. (2004). Cognitive exploration of language and linguistics (Vol. 1): John Benjamins Publishing.

Fodor, J. A. (1981). Imagistic representation. In N. Block (Ed.), Imagery (pp. 63-86). MA: MIT Press.

Furner, J. (2004). Conceptual analysis: A method for understanding information as evidence, and evidence as information. Archival science, 4(3-4), 233-265. 
Garrod, S., Ferrier, G., \& Campbell, S. (1999). In and on: investigating the functional geometry of spatial prepositions. Cognition, 72(2), 167-189.

Gibbs, J. R. W., \& Colston, H. L. (2006). Image schema: The cognitive psychological reality of image schemas and their transformations. In D. Geeraert (Ed.), Cognitive linguistics: Basic reading (pp. 239-268). Berlin: Walter de Gruyter CmbH \& Co. KG.

Gibbs, J. R. W., \& Tendahl, M. (2006). Cognitive effort and effects in metaphor comprehension: Relevance theory and psycholinguistics. Mind \& Language, 21(3), 379403.

Horvath, J. (2018). Conceptual analysis. Retrieved from https://philpapers.org/browse/conceptual-analysis

Jeannerod, M. (1994). The representing brain: Neural correlates of motor intention and imagery. Behavioral and Brain sciences, 17(2), 187-202.

Jones, S. (2002). Antonymy: A corpus-based perspective. London: Routledge.

Kosterec, M. (2016). Methods of conceptual analysis. Filozofia, 71(3), 220-230.

Lakoff, G., \& Johnson, M. (1980). Metaphors we live by. Chicago and London: The University of Chicago Press.

Langacker, R. W. (2002). Concept, image, and symbol: The cognitive basis of grammar (Vol. 1): Walter de Gruyter.

Langacker, R. W. (2008). Cognitive grammar: A basic introduction: Oxford University Press.

Li, C. N., \& Thompson, S. A. (1989). Mandarin Chinese: A functional reference grammar: Univ of California Press.

Lindstromberg, S. (2010). English prepositions explained. Amsterdam: John Benjamins Publishing.

Lyons, J. (1977). Semantics (Vol. 2). Cambridge: Cambridge University Press.

Machado, A., \& Silva, F. J. (2007). Toward a richer view of the scientific method: The role of conceptual analysis. American Psychologist, 62(7), 671-681.

MacInnis, D. J., \& Price, L. L. (1987). The role of imagery in information processing: Review and extensions. Journal of consumer research, 13(4), 473-491.

McArthur, T. B., McArthur, T., \& McArthur, R. (2005). Concise Oxford companion to the English language: Oxford University Press, USA.

Ministry of Education ROC. (Ed.) (2015) Revised Mandarin Chinese Dictionary. Taiwan (ROC): Ministry of Education ROC.

Nishimura, Y. (2007). Prepositions. Taipei County: Maple House Cultural Publishing.

Sperber, D., \& Wilson, D. (1995). Relevance: Communication and cognition. Oxford: Blackwell.

Tendahl, M., \& Gibbs, J. R. W. (2008). Complementary perspectives on metaphor: Cognitive linguistics and relevance theory. Journal of pragmatics, 40(11), 1823-1864.

Ungerer, F., \& Schmid, H.-J. (2013). An introduction to cognitive linguistics (2 ed.). Oxon and New York: Routledge.

Wang, C. (2014). Conceptual metaphors in the uses of prepositions in English and Mandarin: A comparative study. ( $\mathrm{PhD})$, Institute of Education, University of London, UK,

Yule, G. (1996). Pragmatics. In. Oxford Oxford University Press. 
Zhang, N. N. (2007). Root merger in Chinese compounds. Studia Linguistica, 61(2), 170-184.

Zuoyan, S., \& Likun, Q. (2013). Qualia Relations in Chinese Nominal Compounds Containing ontaining Verbal Elements. International Journal of Knowledge and Langauge Processing, 4(1), 1-15.

\section{AUTHOR'S BIO}

Dr Chunying Wang is currently a project assistant professor in the Department of Applied Foreign Languages, Lunghwa University of Science and Technology, Taiwan. He was awarded his PhD in Language in Education from the Institute of Education, University of London, UK in 2014. Dr Wang's research interests majorly include linguistics, language and cognition, and language education. 